\title{
Effect of Cognitive Restructuring and Systematic Desensitization in the Management of Mathophobia among Secondary School Students in Khana L.G.A of Rivers State, Nigeria
}

\author{
Ernest-Ehibudu Ijeoma Regina*, Wayii Augustine Lezorgia \\ Department of Educational Psychology, Guidance and Counselling University of Port-Harcourt, Rivers State, Nigeria \\ *Corresponding author: ijeoma.ernest-ehibudu@uniport.edu.ng
}

\begin{abstract}
This study was conducted to test the effect of cognitive restructuring and systematic desensitization in the management of mathophobia (that is, Mathematics anxiety) among secondary school students in Khana Local Government Area of Rivers State, Nigeria. Five research questions and five null hypotheses were formulated for testing at 0.05 level of significance to guide the study. In executing the study, the pre-test, post-test, and control group experimental research design was adopted using a randomized sample of 120 mathophobic SS2 students drawn from three public secondary schools. The researchers developed an instrument titled "Mathematics Diagnostic Questionnaire” (MDQ) which was adequately assessed for validity and reliability and was used in collecting pre-test and post-test data for the cognitive restructuring, systematic desensitization and control group. Each group received only one type of treatment, with the exception of the control group that received a placebo treatment. Follow-up assessment was conducted after an interval of four weeks after post-test. Data analysis was done using mean, and standard deviation for the research questions, while independent samples and paired sample ttest were used for the hypotheses. The result obtained showed that both cognitive restructuring and systematic desensitization were significantly effective in the management of mathophobia among secondary school students, with systematic desensitization having a greater effect than cognitive restructuring. Also obtained was the fact even after post-test, no statistical difference was obtained for both group. Based on this result, it was recommended that counsellors should not limit themselves to only one technique in handling mathophobic students rather, they should employ eclectic model in counselling.
\end{abstract}

Keywords: cognitive restructuring, systematic desensitization, mathophobia, behaviour modification

Cite This Article: Ernest-Ehibudu Ijeoma Regina, and Wayii Augustine Lezorgia, "Effect of Cognitive Restructuring and Systematic Desensitization in the Management of Mathophobia among Secondary School Students in Khana L.G.A of Rivers State, Nigeria.” American Journal of Educational Research, vol. 5, no. 11 (2017): 1131-1137. doi: 10.12691/education-5-11-3.

\section{Introduction}

In recent times, the acute fall in the performance of secondary school students in Mathematics has been a source of great concern to all stakeholders and as such attracted much research interest. Researchers have come up with several explanations to the poor performance of secondary school students in Mathematics. One of the major causes as identified by some researchers is the fear of Mathematics which she called mathemaphobia. According to Perry (2004) [15], mathophobia (mathematics anxiety) refers to dread of Mathematics that can interfere with manipulating numbers and solving mathematical problems in a wide variety of ordinary life and academic situations. In a similar way, Ashcraft (2002) [2] avers that Mathophobia (Mathematics anxiety) is a feeling of tension, apprehension, or fear that interferes with Mathematics performance. This implies that mathophobia is a trend that is regularly considered while examining the problems of students in Mathematics. Mathematics anxiety is related to poor performance in Mathematics achievement tests and is directly connected with avoidance of Mathematics. According to Schar and Kirk (2001) [17], because math anxiety can cause math avoidance, an empirical dilemma arises. When a highly math-anxious student performs disappointingly on a math question, it could be due to math anxiety or the lack of competency in math because of math avoidance. Ashcraft (2002) [2] suggests that highly anxious students will avoid situations in which they have to perform mathematical calculations. Unfortunately, math avoidance results in less competency, exposure and math practice, leaving students more anxious and mathematically unprepared to achieve.

According to findings at the University of Chicago by Sian Beilock and her group, math anxiety is not simply about being bad at math. After using brain scans, scholars 
confirmed that the anticipation or the thought of solving math actually causes math anxiety. The brain scan showed that the area of the brain that triggered when someone has math anxiety overlaps the same area of the brain where bodily harm is registered (Harms, 2012) [9]. This give credence to the fact that mathophobia is a psychological disorder. It disorganizes people and makes it impossible to adapt to their educational challenges. At times it blocks people's reasoning ability and many forget what is already known under test or examination tension. In fact this ugly situation has interfered with the career and vocational aspirations of most people. Students would simply avoid the object of phobia to jettison their original aspired career or vocation. In the process, career interest becomes jeopardized with a lack of interest and low self-esteem. This, in turn, has affected the technological development of our nation.

Also, Bamidele (2005) [5] expresses that the general impression of students is that Mathematics is an awful subject, but paradoxically it is the foundation scientific progress. This connotes that increasing sophistication of society and technological advancement make Mathematics ever more indispensable in the society. Mathematics remains an unavoidable aspect of our existence and if our society would advance technologically then the subject must be taking seriously in schools. In other words, Mathematics is a core subject that should be given adequate attention by all. It is against this backdrop, that counsellors are needed to render assistance to students at the secondary school level who may have this phobic tendency towards Mathematics, since it is acclaimed that mathophobia is a psychological disorder.

Consequent upon this fact, this research work is intended to evaluate the effect of two behaviour modification techniques in managing mathophobia among secondary school students in Khana Local Government Area of Rivers State, Nigeria. Hence, cognitive restructuring and systematic desensitization are employed in this study. The choice of a cognitive restructuring strategy is due to the current trend in literature of experimental investigations of phobia (mathophobia). It is becoming apparent to researchers (Antoni, 2003; Asikhia, 2014) [1,3] that cognitive restructuring as a technique can bring about changes in a person's thinking or cognitive processes. Thus, the task of therapy involves identifying faulty thought patterns (fear of mathematics) and replacing with more adaptive cognition.

Cognitive restructuring is a type of therapeutic technique, which refutes one's irrational ideas and replaces them with rational ones. Dibatolo, Frost, Dixon and Almodorar (2001) [7] defined cognitive restructuring as employing self-statements, arguments, and disputations to make the client see irrationality in his or her behaviour and to be able to devise positive alternative ways to such irrationality in case the urge arises in the future. Cognitive restructuring is a psychotherapeutic process of learning to identify and dispute irrational or maladaptive thoughts known as cognitive distortions, such as all-or-nothing thinking (splitting), magical thinking, over-generalization, magnification and emotional reasoning, which are commonly associated with any mental health disorder (Gladding, 2009; Ryan and Eric, 2005) [8,16]. The assumption underlying this strategy is that disorders like phobia result from inappropriate irrational or selfdefeating thoughts or beliefs.

Systematic desensitization is a type of behavioural therapy based on the principle of classical conditioning. This therapy aims to remove the fear response of a phobia and substitute a relaxation response to the conditional stimulus gradually using counter conditioning (McLeod, 2015) [12]. Selection of systematic desensitization for this study stems from the relative effectiveness over other single therapeutic strategies in phobia management (mathophobia) as attested by available data (Kleinkneck 1986) [10]. For example, Barer (1968) [6] used systematic desensitization to modify mathophobia among students. Systematic desensitization (S/D) is a behaviour modification technique developed by Joseph Wolpe in 1958, 1969, 1973, and 1982 respectively. The treatment operates on the belief that relaxation and anxiety cannot exist simultaneously, thus a client that can relax comfortably in anxiety-provoking imagination would feel less anxious in real life situation. It is on this basis that the researchers sort to examine the effect of cognitive restructuring $(\mathrm{C} / \mathrm{R})$ and systematic desensitization $(\mathrm{S} / \mathrm{D})$ in the management of mathophobia among secondary school students in Khana L.G.A of Rivers State, Nigeria.

\subsection{Research Questions}

1. What is the effect of cognitive restructuring in the management of mathophobia among secondary school students in Khana Local Government Area?

2. What is the effect of systematic desensitization in the management of mathophobia among students in Khana Local Government Area?

3. What is the relative effect of cognitive restructuring and systematic desensitization in the management of mathophobia among secondary school students in Khana L.G.A?

4. To what extent is the effect of cognitive restructuring technique in the management of mathophobia among secondary school students in Khana LGA retained after treatment?

5. To what extent is the effect of systematic desensitization technique in the management of mathophobia among secondary school students in Khana Local Government Area retained after treatment?

\subsection{Hypotheses}

1. There is no significant difference between students treated with cognitive restructuring and those in the control group in Khana Local Government Area.

2. There is no significant difference between students treated with systematic desensitization and those in the control group in Khana Local Government Area.

3. There is no significant difference in the post and follow-up assessment of students treated with cognitive restructuring technique in Khana Local Government Area.

4. There is no significant difference in the post and follow-up assessment of students treated with cognitive restructuring technique in Khana Local Government Area. 
5. There is no significant difference in the relative effects of the two behaviour modification techniques in the management of mathophobia among secondary school students in Khana LGA of Rivers State.

\subsection{Literature Review}

Asikhia (2014) [3] carried out a study examining the effectiveness of cognitive restructuring on Mathematics anxiety among students in Ogun State. The study employed a 2 × 2 × 3 pre-test, post-test factorial design. The sample consisted of 90 males and 90 females of high, medium and low study habit level who were Mathematics anxious based on their responses to the researcher's adopted instruments namely Mathematics Anxiety Rating Scale-Revised (MARS-R) and Study Habit Inventory (SHI) by Bakare (1977) [4]. The sample was divided into an experimental and a control group. The experimental group received cognitive restructuring treatment while placebo was administered to the control group. Analysis of covariance was used to test the hypothesis formulated. Results of this study showed a significant effect of treatment of cognitive restructuring on students' level of anxiety in Mathematics (F-ratio $=5.81, \mathrm{P}<0.05)$. Asikia study used ANCOVA for analysis while the present study used independent samples t-test and paired samples t-test. It is on this basis that the researchers intend to replicate these findings in the management of mathophobia students in Khana Local Government Area of Rivers State, Nigeria.

Okoiye and Falaye (2011) [13] carried out a study that focuses on the effectiveness of cognitive and group behaviour therapies in managing examination anxiety among academically-at-risk students in Ibadan, Oyo State, Nigeria. The study adopted an experimental research design. One hundred and eighty (180) participants from six secondary schools in three LGAs in Ibadan were used. Assignment of subject was done into two experimental and one control groups. The experimental groups were given ten weeks training in cognitive and group behaviour therapies, while no training was provided for those in the control group. Two validated instruments namely Examination Anxiety Scale and Student Academic SelfEfficacy Scale were adopted and used. Data analysis was done using ANCOVA and t-test. The findings indicated that both treatments significantly affected academicallyat-risk students to manage examination anxiety. Hence, in the final analysis, cognitive behaviour and group therapies are effective in managing examination anxiety among academically-at-risk-students. On this note, it was recommended among others that the school counsellors could adopt the two interventions therapies. Owing to this result, the researchers had no doubt that this technique would be of enormous help in managing mathophobia among students in Khana Local Government Area of Rivers State, Nigeria. While Okoiye and Falaye used ANCOVA and t-test, the present study used only t-test for data analysis.

Antoni (2003) [1] investigated anxious students' academic behavior by using cognitive restructuring to verify if unrealistic self-statements influences academic anxiety, which affects students. In his study, he used 102 students identified as low achievers who were randomly split into experimental and control groups aged between
13-19 years, with a mean of 16 and systematic desensitization of 9.1. He adopted 5 variables which included teacher experience, self-concept, self-statement, school size and peer group. Analyzed data showed that students who used cognitive restructuring in the treatment group, performed better as it was recorded that their anxiety level reduced and their self-esteem boosted, from their post test results. Also, measures of anxiety from the control group, correlated positively, with their performance recorded on their self-statements. This was, therefore, the reason for reduced performance in school subjects which invariably leads to poor academic achievement.

Otta and Ogazie (2014) [14] investigated the effects of systematic desensitization and study behaviour techniques in the reduction of test phobia among in-school adolescents in Abia State. The quasi-experimental research design was used in the study adopting a $3 \times 2$ factorial design. Sixty SS 2 students drawn through stratification were used as the subject. A researcherdeveloped 30 item instrument was used for data collection. T-test and ANCOVA were used for data analysis. The result showed that systematic desensitization and study behaviour technique has a significant effect on the post and follow-up phases.

However, Ventis, Higbee, and Murdock (2001) [18] conducted a study on the effectiveness of systematic desensitization for fear reduction using humorous hierarchy scenes without relaxation. The sample for the study comprises of 40 students (2 men and 38 women) drawn from the College of William and Mary, Williamsburg who were very fearful of spiders. The researcher using a 24 item behavioural approach test with an American Tarantula, subjects were matched on the fear level and randomly assigned to 1 of 3-treatment groups- systematic desensitization, humourdesensitization, and untreated control. Each subject was seen for 6 sessions, including pre-test. Data were analyzed using analysis of covariance of post-test which revealed that the two treatment groups showed a greater reduction in fear while the controls in 3 measures but did not differ from each other. Hence, humour in systematic desensitization reduced fear as effectively as more traditional desensitization.

\section{Methods}

The study adopted a pre-test, post-test and control group quasi-experimental design with the $3 \times 2$ factorial matrix. According to Kpolovie (2010) [11], experimental research is the most powerful and most suitable methodology in investigations for the overt establishment of causal relationships (cause-and-effect relationships) among variables. It ensures dependable specification of the cause of such relationships through control and manipulation of the variables under investigation. In this design, the researchers manipulated two independent variable(s) which are the counselling techniques and its effects observed. Three groups were used for the study; two experimental groups and one control group. One experimental group tagged experimental group I was exposed to the cognitive restructuring technique, the other tagged experimental group II to systematic desensitization technique, and the control group III was not exposed to 
any treatment. All groups were pretested but only the two experimental groups, cognitive restructuring, and systematic desensitization received treatment on mathophobia. The control group did not receive any treatment. After the pre-test, there were post-test on two different sittings on the two experimental groups on cognitive restructuring and systematic desensitization.

Table 1. Randomized Pretest, Post-Test And Control Group

\begin{tabular}{|c|c|c|c|c|c|}
\hline & Group & Pretest & $\begin{array}{c}\text { Independent } \\
\text { Variable }\end{array}$ & Post test 1 & Follow up \\
\hline $\mathrm{R}$ & $\mathrm{E}$ & $\mathrm{Q} 1$ & $\mathrm{X}$ & 02 & 03 \\
\hline $\mathrm{R}$ & $\mathrm{E}$ & $\mathrm{Q} 1$ & $\mathrm{X}$ & 02 & 03 \\
\hline $\mathrm{R}$ & $\mathrm{C}$ & $\mathrm{Q} 1$ & - & 02 & 03 \\
\hline
\end{tabular}

KEY:

$\mathrm{X}=$ The experimental variables (cognitive restructuring and systematic desensitization)

$\mathrm{R}=$ Random assignment of treatment of the groups

$\mathrm{E}=$ Experimental groups

$\mathrm{C}=$ Control group.

$\mathrm{Q} 1=$ Measure before treatment

$02=$ Measure of the dependent variable after treatment

03= Measure of the dependent variable two months after the treatment.

- = The control group received no treatment.

The population consisted of all the SS11 students in the 22 public secondary schools in Khana Local Government Area of Rivers State, Nigeria. SS11 students numbering 2,425 (Post Primary School Board Bori) formed the population. The study sample consisted of one hundred and twenty SS11 students randomly drawn through the ballot system from three co-educational public Secondary Schools in Khana Local Government Area of Rivers State, Nigeria. These were those who indicated phobic-based status as articulated in the Mathophobia Diagnostic Questionnaire that was administered to them by the researchers. After the pre-test selected 40 participants which comprised of 20 males and 20 females to each of the intact groups. These included the two experimental groups and control group. The researchers developed an instrument for this study. tagged Mathophobia Diagnostic Questionnaire (MDQ). It is a 30-item instrument measuring Mathematics anxiety expressed with statements concerned with one's feelings towards Mathematics. A high index of score suggests anxiety disorder while a low index suggests the reverse. The maximum and minimum score possible were 120 and 30 respectively, and a student with 60 and above was identified as Mathematics phobic. The scale has two sections. Section A is to elicit information on idiographic and demographic variables while section $\mathrm{B}$ contains the 30 items of the scale presented in a Likert format of Strongly Agree, Agree, Disagree and Strongly Disagree. The researchers conducted a trial test on 30 students outside the targeted population. A test-retest method of establishing reliability was used on the subjects. This produced a Pearson Product Moment Correlation of stability estimate of 0.85 . The validity of the instruments to be used relied on the vetting by three experts in the field of Educational Psychology, Guidance \& Counselling together with Measurement and Evaluation from the University of Port Harcourt. The reliability was carried out by teaching a selected one class of students from Tai LGA who were not used for the study. The reliability co-efficient of the instruments was established through test-retest method. The initial and re-test scores were correlated using Pearson Product Moment. The following coefficient was obtained for the instruments namely mathophobia diagnostic questionnaire (MDQ) as 0.85 . The coefficient value obtained was high enough to guarantee the use of the instrument as a reliable one for this study. The procedure for the collection of data involved three stages namely: the pre-test stage, post-test, and follow-up stage. Research questions were answered using descriptive statistics of mean and standard deviation, while hypotheses one, two and five were tested using independent samples t-test. Hypotheses three and four were tested using paired sample t-test. All hypotheses were tested at 0.05 level of significance. All analyses were done using SPSS.

\section{Results}

Research Question One: What is the effect of cognitive restructuring in the management of mathophobia among secondary school students in Khana Local Government Area?

Table 2. Mean and standard deviation of cognitive restructuring effect on mathophobia

\begin{tabular}{|lcc|}
\hline Cognitive restructuring & Mean & Standard Deviation \\
Pretest & 75.93 & 9.10 \\
Posttest & 53.25 & 3.97 \\
\hline
\end{tabular}

From the data analysis in Table 2, students treated with cognitive restructuring techniques had a lesser mathophobia post-test mean value of 53.25 (SD = 9.10), compared to their pretest value of 75.93 (SD = 3.97). This indicates that cognitive restructuring technique has a positive effect in reducing mathophobia among students in Khana Local Government Area.

Research Question Two: What is the effect of systematic desensitization in the management of mathophobia among students in Khana Local Government Area?

To answer research question two, mean and standard deviation were used

Table 3. Mean and standard deviation of systematic desensitization effect on mathophobia

\begin{tabular}{|lcc|}
\hline Systematic desensitization & Mean & Standard deviation \\
Pretest & 81.43 & 5.65 \\
Posttest & 53.63 & 6.16 \\
\hline
\end{tabular}

From the data analysis in Table 3, students treated with systematic desensitization techniques had a lesser mathophobia post-test mean value of 53.63 (SD = 5.65), compared to their pretest value of $81.43(\mathrm{SD}=6.16)$. This indicates that systematic desensitization has a positive effect in reducing mathophobia among students in Khana Local Government Area.

Research Question Three: What is the relative effect of cognitive restructuring and systematic desensitization in the management of mathophobia among secondary school students in Khana L.G.A? 
Table 4. Relative effect of cognitive restructuring and systematic desensitization on mathophobia

\begin{tabular}{|llll|}
\hline C/R & Mean(SD) & S/D & Mean(SD) \\
Pre-test & $75.93(9.10)$ & Pre-test & $81.43(5.65)$ \\
Post-test & $53.25(3.97)$ & Post-test & $53.63(6.16)$ \\
Difference & 22.68 & Difference & 27.80 \\
\hline
\end{tabular}

From the data analysis in Table 4, students treated with cognitive restructuring had a mean difference of 22.68 compared to those treated with systematic desensitization that had a mean difference of 27.80. This indicates that systematic desensitization had a greater positive effect in reducing mathophobia than cognitive restructuring.

Research Question Four: To what extent is the effect of cognitive restructuring technique in the management of mathophobia among secondary school students in Khana LGA retained after treatment?

Table 5. Mean and standard deviation of cognitive restructuring after treatment and follow up

\begin{tabular}{|lll|}
\hline Cognitive restructuring & Mean & Standard deviation \\
Post-test & 53.25 & 3.97 \\
Follow up & 55.55 & 4.65 \\
\hline
\end{tabular}

From the data analysis in Table 5, students had a lesser post-test mean of 53.25 ( $\mathrm{SD}=3.97)$, compared to their follow-up mean of 55.55 (SD = 4.65). This indicates that the follow-up yielded a higher mathophobic level compared to the post test.

Research Question Five: To what extent is the effect of systematic desensitization technique in the management of mathophobia among secondary school students in Khana Local Government Area retained after treatment?

Table 6. Mean and standard deviation of systematic desensitization after treatment and follow up

\begin{tabular}{|lll|}
\hline Systematic desensitization & Mean & Standard deviation \\
Post-test & 53.63 & 6.16 \\
Follow up & 54.83 & 5.40 \\
\hline
\end{tabular}

From the data analysis in Table 6, students had a lesser post-test mean of 53.63 (SD $=6.17)$, compared to their follow-up mean of $54.83(\mathrm{SD}=5.40)$. This indicates that there was a slight increase in students' mathophobic level as at follow-up compared to post-test.

Hypothesis one: There is no significant difference between students treated with cognitive restructuring and those in the control group in Khana Local Government Area

Table 7. Independent t-test between cognitive restructure and control group on mathophobia

\begin{tabular}{|cccccccc|}
\hline Group & $\mathrm{N}$ & MEAN & SD & Df & $\mathrm{t}$ & Sig & Decision \\
C/R & 40 & 53.25 & 3.97 & 78 & 23.18 & 0.000 & Reject \\
Control & 40 & 81.28 & 6.53 & & & $\begin{array}{c}\mathrm{Ho}_{1} \\
\mathrm{p}<0.05\end{array}$ & \\
\hline
\end{tabular}

Table 7 shows that the students treated with cognitive restructuring technique had a post-test mean of 53.25 $(\mathrm{SD}=3.97)$, while the control group had a mean of 81.28 (SD =6.23). Further analysis using independent samples t-test yielded $\mathrm{t}(78)=23.18, \mathrm{p}<0.05$. This indicates that a significant difference exists in the mathophobic level of students treated with cognitive restructuring and those in the control group.

Hypothesis Two: There is no significant difference between students treated with systematic desensitization and those in the control group in Khana Local Government Area.

Table 8. Independent t-test between systematic desensitization and control group on mathophobia

\begin{tabular}{|lccccccr|}
\hline Group & N & Mean & SD & Df & T & Sig & Decision \\
Systematic & & & & 78 & 19.49 & 0.000 & Reject \\
Desensitization & 40 & 53.63 & 6.15 & & & $\mathrm{Ho}_{1}$ & \\
Control & 40 & 81.28 & 6.53 & & & $\mathrm{p}<0.05$ & \\
\hline
\end{tabular}

Table 8 shows that students treated with systematic desensitization technique had a post-test mean of 53.63 $(\mathrm{SD}=6.15)$, compared to the control group with a mean of 81.28 (SD =6.53). Further analysis using independent samples t-test yielded $\mathrm{t}(78)=19.49, \mathrm{p}<0.05$. This indicates that a significant difference exists in the mathophobic level of students treated with systematic desensitization and those in the control group.

Hypothesis Three: There is no significant difference in the post and follow-up assessment of students treated with cognitive restructuring technique in Khana Local Government Area.

Table 9. Paired sample t-test of post and follow-up of cognitive restructuring group

\begin{tabular}{|ccccccccc|}
\hline C/R & N & Mean & SD & Df & R & T & Sig & $\begin{array}{c}\text { Decision } \\
\text { Posttest }\end{array}$ \\
40 & 53.25 & 3.97 & 39 & 0.77 & 4.28 & 0.00 & $\begin{array}{c}\text { Reject } \\
\mathrm{HO}_{1} \\
(\mathrm{p}<0.05)\end{array}$ \\
\hline
\end{tabular}

Analysis as displayed in Table 9, revealed that students treated with cognitive restructuring technique had a post-test mean of 53.25 (SD = 3.97), while follow-up test had a mean of 55.55 ( $\mathrm{SD}=4.65)$. Further analysis using paired sample t-test, yielded at $(39)=4.28, \mathrm{p}<0.05$. This suggests that a significant difference exists in the post-test and follow-up assessment of students treated with cognitive restructuring technique. Hence, the null hypothesis was rejected.

Hypothesis four: There is no significant difference in the post and follow-up assessment of students treated with systematic desensitization technique in Khana Local Government Area.

Table 10. Paired sample t-test of post and follow-up of systematic desensitization group

\begin{tabular}{|c|c|c|c|c|c|c|c|c|}
\hline $\mathrm{S} / \mathrm{D}$ & $\mathrm{N}$ & Mean & SD & $\mathrm{df}$ & $\mathrm{R}$ & $\mathrm{T}$ & Sig & Decision \\
\hline Post-test & 40 & 53.63 & 6.16 & 39 & 0.96 & 4.17 & 0.00 & Reject \\
\hline Follow up & 40 & 54.83 & 5.40 & & & & & $\begin{array}{c}\mathrm{HO}_{4} \\
(\mathrm{p}<0.05)\end{array}$ \\
\hline
\end{tabular}


Analysis as displayed in Table 10, revealed that students treated with systematic desensitization technique had a post-test mean of $53.63(\mathrm{SD}=6.16)$, while followup test had a mean of $54.83(\mathrm{SD}=5.40)$. Further analysis using paired sample t-test, yielded a t $(39)=4.17, \mathrm{p}<0.05$. This shows that a significant difference exists in the post and follow-up assessment of students treated with systematic desensitization technique. The null hypothesis was therefore rejected.

Hypothesis Five: There is no significant difference in the relative effects of the two behaviour modification techniques in the management of mathophobia among secondary school students in Khana LGA of Rivers State.

Table 11. Independent t-test between effects of cognitive restructuring and systematic desensitization on mathophobia

\begin{tabular}{|lccccccc|}
\hline $\begin{array}{l}\text { Group } \\
\text { Systematic }\end{array}$ & N & Mean & SD & Df & T & Sig & Decision \\
$\begin{array}{l}\text { desensitization } \\
\text { Cognitive }\end{array}$ & 40 & 53.63 & 6.15 & 78 & 0.324 & 0.000 & Retain \\
Restructuring & 40 & 53.25 & 3.97 & & & & \\
& & & & & & \\
& & & & & & \\
\end{tabular}

Table 11 shows that students treated with systematic desensitization technique had a post-test mean of 53.63 $(\mathrm{SD}=6.15)$, compared to those treated with cognitive restructuring with a mean of 53.25 (SD = 3.97). Further analysis using independent samples t-test yielded $t(78)=$ $0.324, \mathrm{p}>0.05$. This indicates that there is no significant difference in the mathophobic level of students treated with systematic desensitization and those treated with cognitive restructuring.

\section{Discussion}

\subsection{Cognitive Restructuring Technique and Mathophobia}

The result obtained from the study revealed that after the application of treatment, students treated with cognitive restructuring technique had a lesser level of mathophobia as shown by their mean $(53.25$, SD $=3.97)$, when compared to their pre-treatment level of mathophobia $($ mean $=75.93$, $\mathrm{SD}=9.10$ ). This shows that the cognitive restructuring has a positive effect mathophobia management among students in Khana Local Government Area, Nigeria. This result was statistically different from that of the control group. This result obtained from the analysis was expected and not surprising to this researcher because personal observation shows that most students confronts Mathematics with a negative and irrational mindset believing that they can never learn or master the subject and perform in examination assessments or external examinations. Applying cognitive restructuring technique helps such students to identify the irrational beliefs guiding their approach and perspectives of the subject. This technique can help facilitate their self-confidence in the subject and help them develop a more positive mindset towards the subject. This result is similar to that obtained by Asikhia (2014) [3] who found out that cognitive restructuring training was effective in Mathematic anxiety management among students in Ogun State. A similar result was also obtained by Okoiye and Falaye (2011) [13] and Antoni (2003) [1]. Despite an extensive literature review, no previous study has yielded a contrary finding.

\subsection{Systematic Desensitization Technique and Mathophobia}

The result obtained from the study revealed that application of systematic desensitization on students with mathophobia led to a reduction in their mean mathophobic level from 81.43 (SD = 5.65) before treatment to 53.63 $(\mathrm{SD}=6.16)$ after treatment. In addition, it was observed that a statistically significant difference exists in the mathophobic level of students treated with systematic desensitization and those in the control group, $t$ (78), 19.49, $\mathrm{p}<0.05$. This shows that systematic desensitization has a positive effect in the management of mathophobia among students in Khana Local Government Area of Rivers State, Nigeria. The result so far obtained that systematic desensitization had a positive effect in the management of mathophobia among students is expected as most forms of phobia, including mathophobia are phobic responses that are reduced or eliminated by pairing with a series of mental images or real life situations that the person finds progressively more fear provoking. So with the proper application of systematic desensitization which involves identification and arrangement of the anxiety-provoking stimulus items into hierarchical order from the least to the greatest ones; training the clients in relaxation and then desensitizing the clients will go a long way to reducing their fear of Mathematics. Once this fear is reduced or eliminated, students will perform better in mathematics or other related areas. The result from this study is similar to that obtained by Otta and Ogazie (2014) [14] in their study of test anxiety among adolescents in Abia State. Their result showed that systematic desensitization has a positive effect both at the posttreatment and follow-up stages. A similar result was also obtained by Ventis et al. (2001) [18] who found out a reduction in students fear of spider using systematic desensitization technique among College of William and Mary, Williamsburg.

\section{Recommendations}

From the result obtained, it was recommended as follows-

1. It should be made mandatory for all levels of education to have functional guidance and counselling centers manned by professional counsellors who are competent in administering behaviour modifications techniques to those who have mathophobia and other maladaptive behaviours.

2. In-service training should be provided to teachers; especially Mathematics teachers so they can readily identify students with mathophobia, and recommend them for counselling.

3. Mathematics teachers should be discouraged from using discouraging comments on students who may not be doing well in the subjects, but assist them 
in changing their self-defeating thoughts which prevent them from performing optimally in the subjects.

4. Counsellors should not limit themselves to only one technique in their effort to assist students who are identified as mathophobic. Rather, they should adopt an eclectic mindset by adopting various techniques when students need help in managing their mathophobia.

5. Ministry of Education should arrange seminars and workshops aimed at developing counsellors and teachers to adequately understand and appropriately apply behaviour modification techniques.

\section{Conclusion}

The study revealed that cognitive restructuring has a positive effect on the management of mathophobia among students in Khana Local Government Area, Nigeria. Again, it established that the application of systematic desensitization on students with mathophobia led to a reduction in their mathophobic level. This indicates that systematic desensitization has a positive effect in reducing mathophobia among students in Khana Local Government Area. Furthermore, when the comparison of the relative effect of cognitive restructuring and systematic desensitization in the management of mathophobia was done, it was found out that systematic desensitization had a greater positive effect in reducing mathophobia than cognitive restructuring.

\section{References}

[1] Antoni, M. H. (2003). Rational thought replacement. Washington, D. C: APA.

[2] Ashcraft, M. H. (2002). Math anxiety: personal, educational and cognitive consequences. Current Directions in Psychological Science, 11, 181-185.
[3] Asikhia, O. A. (2014). Effect of cognitive restructuring on the reduction of mathematics anxiety among senior secondary school students in Ogun State, Nigeria. International Journal of Education and Research, 2(2), 1-20.

[4] Bakare, A. (1977). Study habits inventory. (SHI) Manual Psychoeducational Research Production. Ibadan: University Press.

[5] Bamidele, R. (2005). Mathematics not a dreadful subject. Daily Sun Newspaper, August, 30:22.

[6] Barer, D. D. (1968). A case of desensitization of tutoring therapy.Exceptional Child, 34, 386-387.

[7] DiBartolo, P. M., Frost, R.O., Dixon, A. \& Almodovar, S. (2001). Can cognitive restructuring reduce the disruption associated with perfectionist concerns .Behaviour Therapy, 32 (1), 167-184.

[8] Gladding, S. (2009). Counselling: A comprehensive review. $6^{\text {th }}$ Columbus: Pearson Education Inc.

[9] Harms, W. (2012). When people worry about math, the brain feels the pain. UChicago News. The University of Chicago 31, October, 2012, web 17, October, 2017.

[10] Kleinknect R.A. (1986). The anxious staff, diagnosis and treatment of fears and phobia: New York: Human Science Press, Inc.

[11] Kpolovie, P. J. (2010). Advanced research methods. Springfield Publishers Ltd: Owerri.

[12] McLeod, S.A. (2015). Systemaic desensitization. Retrieved from www.simplypsychology.org/Systematic-Desensitization.html.

[13] Okoiye, O. E., \& Falaye, A. (2011). Effectiveness of Cognitive and Group Behaviour Therapies in Managing Examination Anxiety among Academically-At-Risk Secondary School Students in Ibadan, Oyo State, Nigeria: Journal of Research in Education and Society, 2,2.

[14] Otta, F.E., \& Ogazie, C.A. (2014). Effects of systematic desensitization and study Behaviour Techniques on the Reduction of Test Phobia among In-School Adolescents in Abia State. World Journal of Educational Research Vol. 1, No. 3, August 2014, pp. 1-7.

[15] Perry, A.B. (2004). Decreasing math anxiety in college students. College Student Journal, 38(2), 19-20.

[16] Ryan, C.M. \& Eric, R.D. (2005). Cognitive emotion regulation in the prediction of depression,anxiety, stress and anger. Personality and Individual Differences, 30, 1249-1260.

[17] Schar, M.H. \& Kirk, E.P. (2001). The relationships among working memory, math anxiety and performance. Journal of Experimental Psychology: General, 130: 224-237.

[18] Ventis, W.L., Higbee, G., \& Murdock, S.A. (2001) Using humor in systematic desensitization to reduce fear. The Journal of General Psychology, 128(2), 241-253. 